\title{
Dual-source chemical vapour deposition of titanium (III) phosphide from titanium tetrachloride and tristrimethylsilylphosphine
}

Christopher S. Blackman ${ }^{\mathrm{a}}$, Claire J. Carmalt ${ }^{\mathrm{a}}$, Shane A. O’Neill ${ }^{\mathrm{a}}$, Ivan P. Parkin ${ }^{\mathrm{a}, ~}$, Leonardo Apostolico ${ }^{\mathrm{b}}$, Kieran C. Molloy ${ }^{\mathrm{b}}$

${ }^{a}$ Department of Chemistry, Christopher Ingold Laboratories, University College London, 20 Gordon Street, London, WC1H OAJ.

${ }^{b}$ Department of Chemistry, University of Bath, Claverton Down, Bath, BA2 7AY

\begin{abstract}
Thin films of titanium (III) phosphide (TiP) have been produced from the dual-source atmospheric pressure CVD reaction of $\mathrm{TiCl}_{4}$ and tristrimethylsilylphosphine. Analysis of the films using EDAX, SEM, glancing angle XRD and XPS is presented.

PACS code 81.15.Gh.
\end{abstract}

Keywords: CVD, thin film, titanium phosphide, tristrimethylsilylphosphine

Titanium (III) phosphide (TiP) is a hard-wearing metallic conductor that is extremely resistant to oxidation [1]. It has been suggested for use as a diffusion barrier for Al/W-metallization [2]. Bulk TiP has been prepared by direct elemental combination [3] and from the solid-state metathesis of $\mathrm{TiI}_{4}$ and $\mathrm{Na}_{3} \mathrm{P}$ [4]. Thin films of TiP have been produced by the gas-phase reaction of $\mathrm{TiCl}_{4}$ and $\mathrm{PCl}_{3}$ under an argon/hydrogen atmosphere at $850-1050{ }^{\circ} \mathrm{C}$ but the high reaction temperature limits

\footnotetext{
* Corresponding author. Tel.: +44(0)2076794669; fax.: +44(0)2076797463.

Email: i.p.parkin@ucl.ac.uk
} 
the choice of substrate for the deposition process [5]. Lower temperature CVD reactions utilising both single-source [6] and dual-source approaches [7] from the reaction of $\mathrm{TiCl}_{4}$ and $\mathrm{PH}_{2} \mathrm{R}(\mathrm{R}=$ cyclohexyl or t-butyl $)$ have been investigated. Tristrimethylsilylphosphine (TTMSP) is a functional equivalent of phosphine $\left(\mathrm{PH}_{3}\right)$ [8] and has been used for the synthesis of main-group single-source precursors to phosphide semiconductors [9] such as the thermolysis of $\left[\mathrm{Cl}_{2} \mathrm{GaP}\left(\mathrm{SiMe}_{3}\right)_{2}\right]_{2}$ leading to gallium phosphide $(\mathrm{GaP})[10]$. However, there are no reports in the literature of its use in dual-source CVD. This is perhaps because of the perception that despite being a distillable liquid (bp $243^{\circ} \mathrm{C}$ ) its vapour pressure is too low for atmospheric pressure CVD [8]. It is this relatively low vapour pressure that gives it an important benefit relative to $\mathrm{PH}_{3}$, that of increased safety and ease of handling. The lack of reports of its use is perhaps surprising because tristrimethylsilylarsine (TTMSA) has been used for the production of GaAs in dual-source CVD reactions with $\mathrm{GaCl}_{3}$ or $\mathrm{Me}_{3} \mathrm{Ga}$ [11]. The boiling points of the two liquids are similar; $48-49{ }^{\circ} \mathrm{C}$ at 0.1 Torr for TTMSA [12] and $50-52{ }^{\circ} \mathrm{C}$ at 0.1 Torr for TTMSP [13]. Herein we report the production of thin films of titanium phosphide from the atmospheric pressure CVD of $\mathrm{TiCl}_{4}$ and TTMSP.

Films were grown on silca-coated float glass $(15 \times 4 \mathrm{~cm})$ using a purpose built atmospheric pressure cold-wall reactor [14]. The precursors were diverted into the gas stream by passing the nitrogen carrier gas through heated bubblers. TTMSP was synthesised according to a modified version of the literature procedure $[15]\left({ }^{31} \mathrm{P}[\mathrm{H}]\right.$ NMR showed a singlet at $\delta-251 \mathrm{ppm}$ (TTMSP) indicating purity $>98 \%$ ). The reaction of $\mathrm{TiCl}_{4}$ with TTMSP was studied under atmospheric pressure CVD conditions. At a substrate temperature of $550{ }^{\circ} \mathrm{C}$ with a run time of 4 minutes $\left(\mathrm{TiCl}_{4}\right.$ 
bubbler temp. $40{ }^{\circ} \mathrm{C}, \mathrm{N}_{2}$ flow rate 0.4 1/min and TTMSP bubbler temp. $200{ }^{\circ} \mathrm{C}, \mathrm{N}_{2}$ flow rate $0.41 / \mathrm{min}$ ) deposition produced an even, gold, mirror-like film. The driving force for the reaction is the elimination of $\mathrm{Me}_{3} \mathrm{SiCl}$ (equation 1). At substrate temperatures below $550{ }^{\circ} \mathrm{C}$ film growth was too slow to produce a film suitable for analysis in a practical time frame.

$3 \mathrm{TiCl}_{4}+4 \mathrm{P}\left(\mathrm{SiMe}_{3}\right)_{3} \longrightarrow 3 \mathrm{TiP}+12 \mathrm{Me}_{3} \mathrm{SiCl}+\mathrm{P}$

[Eqn. 1]

The film produced at $500{ }^{\circ} \mathrm{C}$ was analysed using EDAX, SEM, glancing angle XRD and XPS. Glancing-angle XRD analysis revealed a crystalline phase, which indexed with a hexagonal unit cell of dimensions $\mathrm{a}=3.493(4) \AA$ and $\mathrm{c}=11.74(6) \AA$. This compares favourably with bulk TiP; $a=3.498(1) \AA, c=11.70(1) \AA$ for solid state metathesis prepared material [4] and $a=3.499(1) \AA, c=11.700(6) \AA$ from elemental combination reactions [3]. EDAX showed the film was homogenous over a number of points and had $\mathrm{TiP}_{1.1}$ stoichiometry. XPS showed the first etched layer contained two $\mathrm{O} 1 \mathrm{~s}$ environments, one at $530.8 \mathrm{eV}\left(\mathrm{TiO}_{2} 530.6 \mathrm{eV}\right)$ and one at 532.6 $\mathrm{eV}\left(\mathrm{PO}_{4}{ }^{3-} 532.4 \mathrm{eV}\right)[16]$. In this first layer the Ti $2 \mathrm{p}$ peaks were broad and poorly defined suggesting a number of species, i.e. $\mathrm{TiP}, \mathrm{TiO}_{2}$ and $\mathrm{TiPO}_{4}$. Subsequent etched layers were free of oxygen contamination suggesting the oxide and phosphate formed as the result of post-reaction oxidation. After etching with argon ions the bulk film contained a Ti $2 \mathrm{p}_{3 / 2}$ binding energy of $455.0 \mathrm{eV}(\mathrm{TiP} 454.8 \mathrm{eV}$ ) and the phosphorus $2 p$ ionisation was observed at $128.4 \mathrm{eV}$ (TiP $128.4 \mathrm{eV}$ ) [17]. Carbon contamination was negligible in the bulk film as was chlorine contamination (below detection limit of XPS instrument, i.e. $<1$ atomic \%). No silicon incorporation was observed in any layer of the film. SEM showed a crazy paving surface consistent with an island 
growth mechanism. The film was determined to be $100 \mathrm{~nm}$ thick using SEM giving a growth rate of $\sim 25 \mathrm{~nm} /$ minute.

The film was adherent to the substrate, passed the Scotch tape test and was not abraded by a brass stylus or steel scalpel. The film was resistant to common solvents (THF, DCM, toluene) and to concentrated $\mathrm{HCl}$. Concentrated $\mathrm{HNO}_{3}$ digested the film in 1 week. The film showed almost no transmission in the range $400-1200 \mathrm{~nm}$ although it was highly reflective, particularly in the region $600-1100 \mathrm{~nm}$. Measurement of the room temperature resistivity yielded a value of $\sim 3000 \mu \Omega \mathrm{cm}^{-1}$, indicating metallic-like conduction and comparing well with a value for bulk TiP of $3400 \mu \Omega \mathrm{cm}^{-1}$ [1]. Contact angle measurements showed the film was hydrophobic and no change was observed after irradiation at $254 \mathrm{~nm}$ (BDH 2 × $8 \mathrm{~W}$ germicidal lamp) for 1 hour. SQUID measurement in the range $2 \mathrm{~K}-35 \mathrm{~K}$ indicated the film was not super-conducting. The film showed no decomposition of a test organic material after UV radiation treatment, indicating that it did not function as a photo-catalyst.

In conclusion the first dual-source CVD reaction utilising TTMSP is detailed to produce thin films of high purity, crystalline titanium (III) phosphide (TiP). The films produced via this method are hard, adherent, chemically resistant and show metallic-like conductivity and reflectance. The reaction pathway for deposition was not determined and warrants further investigation, however elimination of $\mathrm{Me}_{3} \mathrm{SiCl}$ is certainly of importance. A previous dual-source route to TiP [7] almost certainly proceeds via a gas-phase adduct of the form $\mathrm{TiCl}_{4}$.(phosphine $)_{2}$ which decomposes on the substrate surface to form TiP and volatile by-products. However in the reaction of $\mathrm{TiCl}_{4}$ with TTMSP in solution a titanium (III) bis-adduct of $\mathrm{TiCl}_{3}(\mathrm{TTMSP})_{2}$ is formed 
[18] and our investigations have shown that this is not a suitable precursor to thin films of TiP. The results suggest that the use of a volatile metal halide with TTMSP in a dual-source CVD reaction produces films of high purity metal phosphide and therefore its use in dual-source CVD could be extended.

CAUTION! The reaction of $\mathrm{TiCl}_{4}$ with TTMSP could conceivably proceed via a $\mathrm{PH}_{3}$ intermediate. $\mathrm{PH}_{3}$ is extremely toxic and can combine explosively with air.

\section{Acknowledgements}

The EPSRC is thanked for Grants GR/M98623 and GR/M82592. CJC is grateful to the Royal Society for a Dorothy Hodkin Fellowship and additional support. Pilkington Glass are thanked for supply of the substrates and Epichem for supply of phosphines in a related project. Mark Green is thanked for the SQUID measurement.

\section{References}

1 R.L. Ripley, J. Less-Common Met. 4 (1962) 496.

2 R. Leutenecker, B. Fröschle, P. Ramm, Microelectronic Eng. $37 / 38$ (1997) 397.

3 T. Lundstrom, P.O. Snell, Acta Chemica Scand. 21 (1967) 1343.

4 R.F. Jarvis, R.M. Jacunibas, R.B. Kaner, Inorg. Chem. 39 (2000) 3243.

5 S. Motojima, T. Wakamatsu, K. Sugiyama, J. Less-Common Met. 82 (1981) 379.

6 T.S. Lewkebandara, J.W. Proscia, C.H. Winter, Chem. Mater. 7 (1995) 1053.

7 C.S. Blackman, C.J. Carmalt, S.A. O’Neill, I.P. Parkin, L. Apostolico, K.C. Molloy, J. Mater. Chem. 11 (2001) 2408.

8 S.M. Stuczynski, R.L. Opila, P. Marsh, J.G. Brennan, M.L. Steigerwald, Chem. Mater. 3 (1991) 379. 
9 W.E. Buhro, Polyhedron, 13 (1994) 1131.

10 R.L. Wells, M.F. Self, A.T. McPhail, S.R. Aubochon, R.C. Woudenberg, J.P.

Jasinski, Organometallics, 12 (1993) 2832.

11 R.L. Wells, Coord. Chem. Rev. 112 (1992) 273.

12 H. Schumann, L. Rosch, J. Organomet. Chem. 55 (1973) 257.

13 H. Schumann, L. Rosch, J. Organomet. Chem. 107 (1974) 854.

14 L.S. Price, I.P. Parkin, A.M.E. Hardy, R.J.H. Clark, T.G. Hibbert, K.C. Molloy, Chem. Mater. 11 (1999) 1792. Note, the coater used in this experiment was half as wide and half as long as detailed in this reference.

15 G. Becker, H. Schmidt, G. Uhl, W. Uhl, Inorg. Synth. 27 (1990) 243.

16 J.A. Rotole, K. Gaskell, A. Comte, P.M.A. Sherwood, J. Vac. Sci. Technol. A 19 (2001) 1176.

17 C.E. Myers, H.F. Franzen, Inorg. Chem. 24 (1985) 1822.

18 D. Fenske, A. Grissinger, Z. anorg. allg. Chem. 595 (1991) 57. 